OPEN ACCESS

Edited by:

Emily Chu,

National Institutes of Health (NIH),

United States

Reviewed by:

Elisa Chavez,

University of the Pacific, United States

Sharat Chandra Pani,

University of Western Ontario, Canada

${ }^{*}$ Correspondence:

Keith A. Mays

kmays@umn.edu

Specialty section:

This article was submitted to

Systems Integration,

a section of the journal

Frontiers in Dental Medicine

Received: 14 March 2021

Accepted: 28 June 2021

Published: 09 August 2021

Citation:

Mays KA (2021) Designing Oral Health

Curriculum That Facilitates Greater Integration of Oral Health Into Overall Health. Front. Dent. Med. 2:680520.

doi: 10.3389/fdmed.2021.680520

\section{Designing Oral Health Curriculum That Facilitates Greater Integration of Oral Health Into Overall Health}

\author{
Keith A. Mays* \\ University of Minnesota School of Dentistry, Minneapolis, MN, United States
}

For several decades, health professions education has been transforming; pedagogical constructs such as active learning, recorded lectures, electronic assessment, asynchronous content delivery, and interprofessional education and practice. However, the typical oral health curriculum has need for further transformation to ensure graduates' ability to function in an integrated health system. There is significant literature outlining associations between oral health and overall health, therefore, it is paramount that oral health learners develop skills to collaborate in an integrated model. Satcher, in 2000, outlined the gravity of oral health inequities and the importance of oral health. He said, "Too little time is devoted to oral health and disease topics in the education of non-dental health professional." However, on the contrary typical oral health curriculum provide knowledge acquisition of topics related to overall health but isn't specifically designed to guide integrated care. In order to increase integrated care, groups like the Interprofessional Education Collaborative (IPEC) have developed competencies for interprofessional education and collaborative practice that guides the training of health professionals. One way to improve integration is accreditation standards that guide transformation as well incorporate IPEC competencies. Having competencies is important to prepare learners to function in clinics like Kaiser Permanente's medical-dental integration model that rely upon teams and teamwork and clarity of roles and responsibilities. This manuscript outlines principle of oral health curriculum that facilitate graduates ability to work in an integrated health system and how that contributes to the improvement overall health of patients.

Keywords: interprofessional education, collaborative practice, oral health, integrated care, curriculum

\section{BACKGROUND}

In the 1800s, Horace H. Hayden and Chapin A. Harris founded the Baltimore College of Dental Surgery and established the first educational program to educate and train dentists with the understanding that it was important to create interdisciplinary connections between medicine and dentistry. In 1926, William J. Gies wrote, "Owing to failure of both physicians and dentists to recognize the fact that the primary objectives of dentistry and of medicine are identical-to keep people well (1)." However, despite this charge from Gies, throughout much of the twentieth century, the majority of dental institutions trained providers with minimal interdisciplinary integration. At the beginning of the twenty first century, the oral health status of Americans was brought to the forefront by the Surgeon General's report, Oral Health in America: A Report of the Surgeon 
General, which cast a brighter light on the inequities in oral health, particularly within the pediatric population. The report states that "oral health is essential to the general health and wellbeing of all Americans." Consequently, in the twenty first century, oral health professionals should be seen as an essential part of the healthcare team with the express intent of improving patient health outcomes, and a contemporary curriculum should prepare oral health graduates with the ability to function in an integrated health system.

More than two decades ago, stakeholders, such as The Institute of Medicine Report (2), the Macy Study (3), and the American Dental Education Association (ADEA) (4, 5), have advocated for systematic curricular change in dental education. These recommendations, in part, were driven by the fact that the predominate curriculum in the twentieth century was a two-by-two model, with biomedical science taught within the first 2 years and clinical experiences in the second 2 years, with minimal integration of biomedical and behavioral science and limited preparation to be a collaborative member of an interdisciplinary healthcare team. A significant portion of curricular change was shepherded by the Commission on Change and Innovation of ADEA in conjunction with dental institutions. Dental institutions embraced competency-based education, problem-based learning, community-based dental education, a reduction in departmental siloes, and community-based dental experiences, to name a few (6). In addition, the transformation of health professions education contributed to pedagogical constructs, such as active learning, recorded lectures, electronic assessment, asynchronous content delivery, and interprofessional education (IPE) and practice (IPP) (7-9). Several dental schools incorporated these elements into their curriculum, and some have completely redesigned their curriculum $(10,11)$. However, gaps in the oral health curricula, such IPE activities that improve collaborative skills, knowledge, and attitudes, and limited experiential interprofessional experiences, constrain the ability for oral health providers to function in an integrated health system. This review outlines modifications for the oral health curriculum that can facilitate the ability of graduates to work in an integrated health system and contribute to the improvement of patient healthcare outcomes.

\section{DESIGNING CURRICULUM FOR INTEGRATION OF ORAL HEALTH AND SYSTEMIC HEALTH}

It is important to acknowledge that the dental curriculum in US dental schools has fundamentally strong components that prepare graduates with a licensure-ready status. By integrating biomedical, behavioral, and clinical science didactic contents with simulated clinical- and patient-based clinical experiences, students are efficiently prepared to enter the healthcare workforce. This 4 year equivalent model has successfully produced practice ready providers, and the following recommendations are intended to be designed within a 4 year model.
One of the shortcomings of the traditional model is the siloed approach to delivering content. Additionally, this siloed approach delivered biomedical content in the first 2 years and potentially contributed to a belief by some learners that the biomedical sciences could be disconnected from the clinical care of oral diseases. Furthermore, the National Board of Dental Examination administered a two-part examination, which reemphasized the separation of biomedical science content from the clinical sciences. However, the Joint Commission recently discontinued the examination in the separated format and has ushered in an integrated biomedical, behavioral, and clinical sciences format. The twenty first century contemporary curriculum should be delivered in a manner that emphasizes the concept that the mouth is connected to the body and that oral diseases have associations with systemic diseases. This type of curriculum will deliver biomedical, behavioral, and clinical sciences content in an integrated format throughout the 4 year curriculum.

Haden et al. (6) surveyed the academic and associate deans of dental schools about curriculum format and reported that schools believed future curriculum should be arranged around themes, not disciplinary boundaries, with a blending of basic and clinical sciences. This may necessitate having foundation or primer courses to deliver essential knowledge prior to these integrated sessions, which would facilitate the retention of knowledge and reinforce the need for integrated care of patients. This curriculum format would require that some biomedical science, in some format, be presented later in the curriculum to reinforce the relationship of biomedical and behavioral science to the clinical care of patients. A few examples of this type of integration have been described in the literature, although many programs have introduced some integrations without documenting them in the published literature $(10,11)$. An example of this is the integrated casebased seminar at the University of Minnesota School of Dentistry, which is a team-taught course with faculty from multiple disciplines. One clinical faculty in conjunction with a biomedical or behavioral science faculty develops a case. This course is delivered after the biomedical courses have been completed and just before entering the clinic to reinforce the need for integrated care.

Curriculum revisions should be a transformative process that leads to substantive modifications that provide oral health professionals the ability to work in an integrated health system, collaborating with other health professionals and improving patient outcomes $(12,13)$. The association between systemic and oral health is well-documented in literature (14-16). Schenkein and Loos (15) noted that there was a statistically significant association between an increased risk of cardiovascular diseases and elevated levels of circulating inflammatory mediators that are commonly associated with periodontal disease. Jeffcoat et al. (16), in a retrospective analysis of linked medical and dental insurance records, reported that there was a statistically significant reduction in treatment cost for pregnant women who received treatment for their clinically diagnosed periodontal disease compared to those who were untreated or undertreated. Lamster and Myers-Wright (13), suggested that 
oral health practice was changing and that "oral healthcare providers need to be comfortable treating these older, medically complex patients, which includes an understanding of how chronic diseases affect a person's ability to tolerate dental care and the linkages between chronic disease and oral disease". Curriculum transformation must continue to train graduates to prevent, diagnose, and treat oral diseases and prepare them to contribute to the improvement of overall health (12). Such a curriculum would better prepare graduates to contribute to the improvement of overall health by identifying hypertension, providing smoking cessation plans for patients, identifying undiagnosed diabetes, contribute to the management of sleep apnea, screen for osteoporosis, and assist the management of obesity (17). An ideal curriculum would be structured in such a manner that it facilitates the oral health provider as an integral member of a team that functions to improve healthcare and patient outcomes.

\section{INTERPROFESSIONAL EDUCATION}

While IPE has been a part of the conversation in healthcare since the 1970s, significant momentum was gained in 2016 by the assembly of an expert panel of representatives from health professional schools who convened to develop a set of competencies for interprofessional collaborative practice (ICP) $(18,19)$. Currently, dental education has competencies for two oral health professionals: the general dentist and the entry-level dental hygienist $(20,21)$. In addition, individual institutions oftentimes supplement these with institutionally specific core competencies that mimic these two documents to meet institutional goals. The competencies of the Interprofessional Education Collaboration (IPEC) provide guidelines that prepare health professional learners to provide patient and familycentered care and team-based care that is "community and population oriented; process oriented; linked to learning activities, educational strategies, and behavioral assessments that are developmentally appropriate for the learner: able to be integrated across the learning continuum; sensitive to the systems context and applicable across professions..." (19). A recent systematic review reported IPE activities as an effective tool for improving a learner's "attitude toward interdisciplinary teamwork, communication, shared problemsolving, and knowledge and skills in preparation for collaboration with other members of interdisciplinary teams." Casa-Levine (22), reported that dental hygiene faculty and administrators had high regard for IPE and that it could enhance patient care and help hygiene learners be more effective team members. The incorporation of IPEC competencies with didactic and experiential interprofessional content into the dental and dental hygiene curriculum is a way to improve the abilities of learners to work as team members with other health professionals.

The 2010 survey of the dental curriculum reported that most dental institutions were increasing community-based clinical experience (CBCE) as a significant aspect of their curriculum, with $46 \%$ having completed the process, $33 \%$ in progress, and
$19 \%$ having a 3 year priority (6). Additional studies have identified that $\mathrm{CBCE}$ has an impact on improving access to care, providing supplemental experiences, and enhancing the ability of a student to work with diverse populations (23, 24). A recent editorial discussed an initiative that created a nurse-led community-based model of IPE and the lessons learned, but fundamentally, it highlights how partnering with community partners provided students with handson experience in how social determinants of health impact patients and how their care impacts vulnerable populations (25). One participant school was a collaboration between a school of dentistry and a nursing school, where students increased their self-reported interprofessional competencies (26). When designing oral health professional curriculum, consideration should include interprofessional experiences that improve the ability of dentists and dental hygienists to be full members of the health team, improving the overall health of a patient and positively impacting a community with limited access.

\section{ACCREDITATION}

One of the critical areas in driving curricular change is the role that regulatory and accrediting agencies play in institutions implementing an innovative or pedagogical transformation.

In 2014, the Health Resource and Services Administration (HRSA) and the United States Department of Health and Human Services assembled an expert panel to develop a set of interprofessional oral health competencies for all primary care health providers $(3,27)$. One response to this call was the establishment of a validated set of competencies for nurse practitioners (28). Oral health was specifically identified within this updated nurse practitioner curriculum and was suggested to be a core competency element. To this end, nurse-practitioner programs are integrating oral health into primary care and are positioned to help reduce oral health inequities.

In 2019, the National Center on Interprofessional Education facilitated a consensus conference of 25 accreditors, titled the Health Professions Accreditors Collaborative (HPAC), and one outcome of this was a guidance document (29). In addition, the Accreditation Council on Graduate Medical Education convened a similar national collaborative of 35 national organizations, called the National Collaborative for Improving Clinical Learning Environments (NCICLE), who have released recommendations for interprofessional clinical learning environments (30). The National Center on Interprofessional Education has partnered with NCICLE to develop a model of using design thinking with these recommendations (Brandt B, Personal Communications, June 8, 2021). These initiatives by accrediting agencies will continue to be instrumental in guiding curricular transformation that will ultimately produce providers who contribute to improving patient outcomes. These examples highlight the important role of accrediting agencies and other stakeholders in the transformation of health professional education and downstream patient care and outcomes. 


\section{OPPORTUNITIES FOR PARTNERSHIPS}

One of the potential outcomes for ICP is the benefits for the patient, which is captured in the elements of the triple aim. A recent article describes how pharmacists created an interprofessional collaboration with a local public health department to provide medication therapy management services (31). As a part of routine medical care, pharmacists provided a comprehensive review of medications for patients and found 719 medication errors and improved patient compliance. The dental office and dental public health and Federally Qualified Health Center (FQHC) clinics would also provide an excellent opportunity to interact with patients needing similar services. To that end, if similar programs were designed within dental school clinics, it could prepare oral health students with the skills to be team members in similar collaborations. A recent study evaluated the feasibility of providing medication therapy management in a dental school clinic and reported identifying patients with several chronic conditions: $64 \%$ had hypertension, $34 \%$ had diabetes, and $10.5 \%$ reported smoking cigarettes and identified drug therapy problems, of which "needs additional drug therapy" was the most common (32). Therefore, creating more collaborations with pharmacy and dentistry, in both the dental education clinics and community clinics, is a potential opportunity to help lower patient cost and improve patient health.

Studies have evaluated the perspective of learners; in a nursing and pharmacy collaboration, a pretest and a posttest revealed that both learner types improved scores on the interdisciplinary Education Perception Scale and the Care Decisions evaluation tools. More specifically, there was an increased awareness of the role of each learner in the management of pain (33).

One study recruited first-year pediatric nurse practitioners to participate in an interdisciplinary oral health educational intervention and demonstrated that the interprofessional experiences resulted in nurse practitioners being more knowledgeable about oral health and more confident in providing oral health counseling (34).

\section{CURRENT KNOWLEDGE ON IMPACT OF INTERPROFESSIONAL EDUCATION}

Reeves et al. (35), in a Cochrane review explained about how IPE affects professional practice and healthcare outcomes. The study updated findings from a 2008 study that evaluated how the use of IPE improves collaboration of healthcare professionals and patient care outcomes (36). The 2008 study resulted in six studies that met the criterion, and the 2013 update included nine additional studies that met the criterion. The results demonstrated that seven studies had positive healthcare processes and patient outcomes, four studies had positive and neutral, and four studies reported no effects from IPE. It is important to note that these studies were performed in different clinical practice types and different IPE interventions.
Dyesset al. (37) evaluated the impact of IPE on health professional students. The study eligibility required for three or more healthcare professional learner types to participate in an IPE activity and for didactic coursework to be included. Seven studies were selected that met the search criterion and demonstrated that IPE improved the attitudes of learners toward interdisciplinary teamwork, communication, shared problem-solving, and gaining knowledge and skills that prepared them to work on a collaborative interdisciplinary healthcare team.

Spaulding et al. (38) performed a systematic review to assess the impact of IPE on changing the attitudes and perceptions of learners, the acquisition of knowledge about the role of other healthcare professions, the development of collaborative skills, and the changes in perceived or actual collaborative behavior. This review studied IPE interventions aimed at learners in health and social disciplines, such as physicians, pharmacists, nurses, psychologists, physical therapists, occupational therapists, dieticians, and social workers. The intervention was defined as any activity with two or more learners engaged in an interactive learning experience designed for the explicit purpose of improving interprofessional collaboration or improving the health and well-being of patients and clients. The findings demonstrated that IPE was effective in improving the attitudes of learners and professionals toward other disciplines and the value of a team-based approach to improving patient outcomes.

\section{SUMMARY}

During the first two decades of the twenty first century, dental education has made strides in improving their curriculum. In order to continually advance the education of oral health professionals, there must be ongoing revisions. Oral health professionals are essential members of the health team, and curriculum revisions should ensure that graduates are prepared to function at the highest level of their scope and that scope can be expanded to include the improvement of overall health. A curriculum should be developed that integrates biomedical, behavioral, and clinical sciences throughout the entire program. In addition, a strong IPE program will prepare learners to work with other health professionals. One way to facilitate this integration would be to develop experiences that guide transformation and the incorporation of IPEC competencies. Additionally, the resources and policy change created by accrediting agencies are invaluable to the transformation of health professional education. Having competencies is important to prepare learners to function in clinics like the medical-dental integration model of Kaiser Permanente, which relies upon teams and teamwork and the clarity of roles and responsibilities. Training health professionals in an interprofessional manner requires shifts in the curriculum to graduate providers with the skills to function in a collaborative environment. 


\section{DATA AVAILABILITY STATEMENT}

The original contributions presented in the study are included in the article/supplementary material, further inquiries can be directed to the corresponding author/s.

\section{REFERENCES}

1. Gies WJ. Dental education in the United States and Canada. A report to the Carnegie Foundation for the advancement of teaching. 1926. J Am Coll Dent. (2012) 79:32-49.

2. Field MJ, ed. Dental Education at the Crossroads: Challenges and Change. An Institute of Medicine Report. Washington, DC: National Academy Press (1995).

3. Formicola AJ, Bailit $\mathrm{Hl}$, Beazoglou TJ, Tedesco. The Macy study: a framework for consensus. J Dent Educ. (2008) 72:95-7. doi: 10.1002/j.0022-0337.2008.72.2_suppl.tb04486.x

4. ADEA Commission on Change and Innovation in Dental Education. Beyond the Crossroads: Change and Innovation in Dental Education. Washington, DC: American Dental Education Association (2009).

5. Kassebaum DK, Tedesco LA. The $21^{\text {st }}$-century dental curriculum: a framework for understanding current models. J Dent Educ. (2017) 81:eS13S21. doi: 10.21815/JDE.017.002

6. Haden NK, Hendricson WD, Kassebaum DK, Ranney RR, Weinstein G, Anderson EL, et al. Curriculum change in dental education, 2003-09. J Dent Educ. (2010) 74:539-57. doi: 10.1002/j.0022-0337.2010.74.5.tb04901.x

7. Hew KF, Lo CK. Flipped classroom improves student learning in health professions education: a meta-analysis. BMC Med Educ. (2018) 18:38. doi: 10.1186/s12909-018-1144-z

8. Schmidt HG, Rotgans JI, Yew EH. The process of problembased learning: what works and why. Med Educ. (2011) 20:792-806. doi: 10.1111/j.1365-2923.2011.04035.x

9. Bridges DR, Davidson RA, Odegard PS, Maki IV, Tomkowiak J. Interprofessional collaboration: three best practice models of interprofessional education. Med Educ Online. (2011) 16:1. doi: 10.3402/meo.v16i0.6035

10. Ditmyer MM, Mobley CC, Davenport WD. Evaluation of an integrative model for professional development and research in a dental curriculum. J Dent Educ. (2014) 78:368-79. doi: 10.1002/j.0022-0337.2014.78.3.tb05687.x

11. Nadershahi NA, Bender DJ, Beck L, Alexander S. A case study on development of an integrated, multidisciplinary dental curriculum. J Dent Educ. (2013) 77:679-87. doi: 10.1002/j.0022-0337.2013.77.6.tb05519.x

12. Mays KA. The ability of oral health professionals to significantly influence improving overall health. J Dent Educ. (2021) 85:7-10. doi: 10.1002/jdd.12338

13. Lamster IB, Myers-Wright N. Oral health care in the future: expansion of the scope of dental practice to improve health. J Dent Educ. (2017) 81:e8390. doi: 10.21815/JDE.017.038

14. Engebretson S, Kocher T. Evidence that periodontal treatment improves diabetes outcomes: a systematic and meta-analysis. J Periodontal. (2013) 84:S153-69. doi: 10.1902/jop.2013.1340017

15. Schenkein HA, Loos BG. Inflammatory mechanisms linking periodontal diseases to cardiovascular diseases. J Periodontal. (2013) 84:S51-69. doi: 10.1902/jop.2013.134006

16. Jeffcoat MK, Jeffcoat RL, Gladowski PA, Bramson JB, Blum JJ. Impact of periodontal therapy on general health. Am J Prev Med. (2014) 47:16674. doi: 10.1016/j.amepre.2014.04.001

17. Lamster IB, Eaves K. A model for dental practice in the $21^{\text {st }}$ Century. Am J Pub Health. (2011) 101:1825-30. doi: 10.2105/AJPH.2011.300234

18. Interprofessional Education Collaborative Expert Panel. Core Competencies for Interprofessional Collaborative Practice: Report of an Expert Panel. Washington, DC: Interprofessional Education Collaborative(2011).

19. Interprofessional Education Collaborative. Core Competencies for Interprofessional Collaborative Practice: 2016 Update. Washington, DC: Interprofessional Education Collaborative (2016).

20. ADEA Competencies for Entry into the Allied Dental Professions: (As approved by the 2011 ADEA House of Delegates). J Dent Educ. (2017) 81:853-60. doi: 10.1002/j.0022-0337.2017.81.7.'tb06301.x

\section{AUTHOR CONTRIBUTIONS}

The author confirms being the sole
contributor of this work and has approved it
for publication.

21. ADEA Competencies for the New General Dentist: (As approved by the 2008 ADEA House of Delegates). J Dent Educ. (2017) 81:844-7. doi: 10.1002/j.0022-0337.2017.81.7.tb06299.x

22. Casa-Levine $C$. The value of interprofessional education: assessing the attitudes of dental hygiene administrators and faculty. J Dent Hyg. (2017) 91:49-58.

23. Mays KA. An analysis of community based-dental education in US dental schools. J Dent Educ. (2016) 80:118895. doi: 10.1002/j.0022-0337.2016.80.10.tb06201.x

24. Smith PD, Mays KA. Incorporation of structural competency into community-based dental education programs at US dental schools. J Dent Educ. (2019) 83:1289-95. doi: 10.21815/JDE.019.130

25. Brandt BF, Barton AJ. Getting started with interprofessional practice and education in community-based settings. J Nurs Educ. (2020) 59:2434. doi: 10.3928/01484834-20200422-01

26. Greenberg SA, Hartnett E, Berkowitz GS, Schenkel AB, Chong C, Cipollina J, et al. Senior oral health: a community-based, interprofessional educational experience for nursing and dental students. J Gerontol Nurs. (2020) 46:37-45. doi: 10.3928/00989134-20200527-03

27. Health Resources and Services Administration. Integration of Oral Health and Primary Care Practice. (2014). Available online at: http://www.hrsa. gov/publichealth/clinical/oralhealth/primarycare/integrationoforalhealth (accessed June 7, 2021).

28. National Organization of Nurse Practitioner Faculties, NP Core Competencies Content Work Group. Nurse Practitioner Core Competencies Content. (2017) Available online at: https://cdn.ymaws.com/www.nonpf.org/resource/resmgr/ competencies/2017_NPCoreComps_with_Curric.pdf (accessed June 7, 2021).

29. Health Professions Accreditors Collaborative. Guidance on Developing Quality Interprofessional Education for the Health Professions. Chicago, IL: Health Professions Accreditors Collaborative (2019). Available online at: https://nexusipe.org/informing/about-national center/news/ipe-guidance (accessed June 7, 2021).

30. Weiss KB, Passiment M, Rioordan L, Wagner R. For improving the clinical learning environment IP-CLE report work group achieving the optimal interprofessional clinical learning environment. In: Proceedings From an NCICLE Symposium. (2019). Available online at: http://ncicle.org (accessed June 8, 2021).

31. Nuffer W, Dye L, Decker S. Integrating pharmacist MTM services into medical clinics as part of a health department partnership project. Innov Pharm. (2019) 10. doi: 10.24926/iip.v10i4.2129

32. Branch-Mays GL, Pittenger AL, Willaimson K, Milone A, Hein E, Thierer T. An interprofessional education and collaborative practice model for dentistry and pharmacy. J Dent Educ. (2017) 81:1413-20. doi: 10.21815/JDE. 017.101

33. Simko LC, Rhodes DC, McGinnis KA, Fiedor, J. Students' perspectives on Interprofessional Teamwork Before and after an interprofessional Pain Education Course. Am J Pharm Educ. (2017) 81:104. doi: 10.5688/ajpe 816104

34. Golinveaux J, Gerbert B, Cheng J, Duderstadt K, Alkon A, Mullen S, et al. Oral health education for pediatric nurse practitioner students. J Dent Educ. (2013) 77:581-90. doi: 10.1002/j.0022-0337.2013.77. 5.tb05506.x

35. Reeves S, Perrier L, Goldman J, Freeth D, Zwarenstein M. Interprofessional education: effects on professional practice and healthcare outcomes. Cochrane Database Syst Rev. (2013) 2013:CD002213. doi: 10.1002/14651858.CD002213.pub3

36. Reeves S, Zwarenstein M, Goldman J, Barr H, Freeth D, Hammick M, et al. Interprofessional education: effects on professional practice and health care outcomes. Cochrane Database Syst Rev. (2008) CD002213. doi: 10.1002/14651858.CD002213.pub2 
37. Dyess, AL, Brown, JS, Brown, ND, Flautt, KM, Barnes, LJ. Impact of interprofessional education on students of the health professions: a systematic review. J Educ Eval Health Prof. (2019) 16:33. doi: 10.3352/jeehp.201 9.16 .33

38. Spaulding EA, Marvel FA, Jacob E, Rahman A, Hansen BA, Hanyok LA, et al. (2019). Interprofessional education and collaboration among healthcare students and professionals: a systematic review and call for action. $J$ Interprofess Care. (2019). doi: 10.1080/13561820.2019.1697214

Conflict of Interest: The author declares that the research was conducted in the absence of any commercial or financial relationships that could be construed as a potential conflict of interest.
Publisher's Note: All claims expressed in this article are solely those of the authors and do not necessarily represent those of their affiliated organizations, or those of the publisher, the editors and the reviewers. Any product that may be evaluated in this article, or claim that may be made by its manufacturer, is not guaranteed or endorsed by the publisher.

Copyright $\odot 2021$ Mays. This is an open-access article distributed under the terms of the Creative Commons Attribution License (CC BY). The use, distribution or reproduction in other forums is permitted, provided the original author(s) and the copyright owner(s) are credited and that the original publication in this journal is cited, in accordance with accepted academic practice. No use, distribution or reproduction is permitted which does not comply with these terms. 